\title{
Transplante cardíaco
}

\section{Cardiac transplantation}

\author{
Alfredo Inácio Fiorelli' ${ }^{1}$ José de Lima Oliveira Jr. ${ }^{2}$, \\ Noedir A. G. Stolf ${ }^{3}$
}

Fiorelli Al, Oliveira Jr. J de L, Stolf NAG. Transplante cardíaco. Rev Med (São Paulo). 2009 jul.-set.;88(3) ed. especial:123-37.

\begin{abstract}
RESUMO: A incidência da insuficiência cardíaca tem aumentado progressivamente nos últimos anos em função do aumento da longevidade da população, dos avanços no tratamento do infarto agudo com o uso de trombolíticos e de angioplastia, da ampliação das intervenções cardíacas e da melhora no diagnóstico da síndrome. Com as recentes modificações incorporadas no tratamento farmacológico houve sensível melhora na sobrevida dos pacientes. Todavia, a evolução da cardiomiopatia para formas terminais é inexorável pelas características da doença e, nessas situações, o transplante pode ser a única alternativa eficaz. O transplante cardíaco é a única forma eficaz de restaurar as funções hemodinâmicas do paciente, contudo apresenta limitações de diferentes ordens, não se aplicando a todos os candidatos. A carência de órgãos viáveis é um dos maiores fatores impeditivos no desenvolvimento dos transplantes. Este problema se torna mais evidente quando se trata de órgãos que são mais sensíveis às injúrias do choque e da isquemia. Em nosso meio, apesar dos grandes avanços conseguidos na legislação sobre transplantes de órgãos ainda existe carência de uma política de saúde efetiva voltada a fomentar a captação e a manutenção adequada dos doadores para que esta situação possa ser revertida. Os imunossupressores modernos oferecem bons resultados no controle dos episódios de rejeição a despeito da falta de maior especificidade. Os efeitos colaterais ainda são preocupantes e requerem controle rígido dos pacientes em longo prazo. A qualidade dos órgãos doados e o estado clínico grave dos candidatos que chegam aos centros de transplante são os principais fatores responsáveis pelos resultados insatisfatórios na fase imediata ao transplante de coração. O presente estudo visa apresentar uma revisão das principais etapas que envolvem o transplante cardíaco.
\end{abstract}

DESCRITORES: Insuficiência cardíaca. Transplante de coração. Imunossupressão.

\footnotetext{
1. Professor Colaborador e Doutor em Cirurgia Cardiopulmonar pela Faculdade de Medicina da Universidade de São Paulo. Diretor do Transplante Cardíaco Adulto do Instituto do Coração do Hospital das Clínicas da Faculdade de Medicina da Universidade de São Paulo. Médico-Supervisor da Liga de Transplante Cardíaco da FMUSP e InCor.

2. Professor Colaborador e Doutor em Cirurgia Cardiopulmonar pela Faculdade de Medicina da Universidade de São Paulo. Aluno do Curso de Extensão Universitária em Transplante Cardíaco e Assistência Circulatória Mecânica da Faculdade de Medicina da Universidade de São Paulo.

3. Professor Titular de Cirurgia Cardiovascular da Faculdade de Medicina da Universidade de São Paulo. Diretor do Instituto do Coração do Hospital das Clínicas da Faculdade de Medicina da Universidade de São Paulo.
} 


\section{INTRODUÇÃO}

C arrel e Guthrie ${ }^{1}$, em 1905, realizaram despretensiosamente o primeiro transplante cardíaco heterotópico implantando o coração de um cão na região cervical de outro animal. Todavia, a intenção dos pesquisadores estava voltada para o desenvolvimento da cirurgia vascular. Essa linha de pesquisa foi tão importante na época que conferiu ao primeiro autor o premio Nobel de fisiologia em 1915.

Nos anos seguintes, as pesquisas experimentais prosseguiram lentamente limitadas pela própria praticidade do método; todavia, com o desenvolvimento da circulação extracorpórea, os estudos foram retomados com vistas ao transplante ortotópico. Assim, em 1960, Lower e Shumway² obtiveram as primeiras séries de transplantes ortotópicos experimentais com sucesso, cujos princípios técnicos foram aplicados mais tarde nos primeiros transplantes em humanos e permaneceram praticamente inalterados até recentemente com a denominada técnica clássica. O primeiro transplante cardíaco humano foi realizado por Hardy et al. ${ }^{3}$, em 1964, quando transplantaram coração de macaco em um paciente em choque cardiogênico grave, porém, sem sucesso; contudo, esse feito teve por mérito demonstrar a exeqüibilidade do método.

Em 1966, Lower transplantou com sucesso, em macacos, corações de cadáveres que eram ressuscitados para doação de rins. Muito embora seus estudos fossem bem conhecidos, nunca foram publicados.

Barnard $^{4}$, de forma surpreendente, em 3 de dezembro de 1967, na Universidade de Cape Town, África do Sul, deu o passo decisivo no transplante cardíaco em humanos: seu paciente teve boa evolução clínica inicial, falecendo no $18^{\circ}$ dia de pós-operatório em conseqüência de infecção pulmonar. Kantrowitz et al., três dias após esse evento, realizaram o segundo transplante mundial em um paciente com 18 dias de vida, portador da doença de Ebstein, cuja sobrevida foi de apenas seis horas. Em 2 de janeiro de 1968, Barnard realizou o seu segundo transplante em um paciente portador de miocardiopatia isquêmica, e Shumway, em 6 de janeiro de 1968, o quarto do mundo. A partir de então, o interesse pelos transplantes cardíacos estendeu-se de tal forma que já no ano seguinte foram operados 101 pacientes.

Zerbini e Decourt ${ }^{5}$, em 26 de maio de 1968 , realizaram o primeiro transplante cardíaco da América Latina e o décimo sétimo no mundo, em um paciente portador de miocardiopatia dilatada. Dois outros pacientes foram operados, um deles com sobrevida superior a um ano, antes que esse programa fosse interrompido por dificuldades no controle da rejeição e infecção. Essa mesma atitude já vinha se estendendo em diferentes centros que tinham iniciado os seus programas pelo mesmo motivo.

Todavia, os maus resultados obtidos com o novo método não desmotivaram a equipe da Universidade de Stanford que, liderada por Shumway que manteve ativo o seu programa. Essa atitude foi ainda seguida por outros poucos grupos, porém foi fundamental para se estabelecerem os critérios clássicos quanto à seleção dos doadores, dos receptores e à própria condução do transplante. A experiência acumulada nesse período propiciou importantes subsídios para a retomada dos transplantes nos anos de 1980, com a introdução da ciclosporina no esquema imunossupressor. Grattan et al. ${ }^{6}$, em 1990, descreveram a experiência acumulada de oito anos de transplante cardíaco, agora com o uso da ciclosporina no qual se pode notar importante melhora da sobrevida dos pacientes para $80,7 \%$ no primeiro ano e $59,7 \%$ no quinto ano após a operação.

O registro mais recente da International Society for Heart and Lung Transplantation, de 2008, apresenta a experiência acumulada de mais de 74 000 transplantes cardíacos realizados em diferentes centros espalhados por diversos países, dos quais mais da metade realizados nos Estados Unidos da América7. Em 1999, foi estabelecida a I Diretriz sobre Transplante Cardíaco ${ }^{8}$ no Brasil e até então haviam sido registrados 792 transplantes cardíacos, realizados em 16 centros ativos, e atualmente esse números praticamente dobraram. O transplante cardíaco em nosso meio tem crescido de forma muito tímida por uma série de razões que passam por diferentes aspectos, como a necessidade de doadores de melhor qualidade e a falta de interesse dos próprios hospitais na manutenção de programas ativos pela remuneração que não atende os custos reais.

\section{SELEÇÃO DOS CANDIDATOS AOTRANSPLANTE DE CORAÇÃO}

\section{Insuficiência cardíaca - quadro clínico}

A incidência da insuficiência cardíaca tem aumentado nos últimos anos em função do acréscimo na expectativa de vida, melhora do diagnóstico, evolução mais favorável do infarto agudo e dos progressos na cirurgia cardíaca. A introdução dos inibidores da enzima de conversão da angiotensina e dos beta-bloqueadores interferiu de forma decisiva na evolução natural da insuficiência cardíaca, permitindo prolongar a indicação do transplante. 
A seleção dos candidatos ao transplante deve ser criteriosa, com identificação dos fatores de risco e de enfermidades coexistentes. Dentre os principais fatores de mau prognóstico de sobrevida, destacandose pela importância: fração de ejeção ventricular reduzida, a classe funcional III/IV (NYHA), elevação das catecolaminas séricas, hiponatremia, pressão capilar pulmonar elevada, índice cardíaco reduzido, arritmias ventriculares e consumo máximo de oxigênio
$\left(\mathrm{VO}_{2} \max \right)$ reduzido durante exercício. Mancini et al. ${ }^{9}$, em 1991, observaram que pacientes com $\mathrm{VO}_{2} \max$ superior a $14 \mathrm{ml} / \mathrm{Kg} / \mathrm{min}$ apresentavam expectativa de vida em um ano de $94 \%$, sem transplante. Ao contrário daqueles que apresentavam índice inferior à $10 \mathrm{ml} / \mathrm{Kg} /$ min, nos quais a expectativa de vida era inferior a $30 \%$ em um ano. No Quadro 1 encontram-se descritos os principais fatores a serem analisados na avaliação clínica dos candidatos ao transplante.

QUADRO 1. Avaliação do candidato ao transplante cardíaco

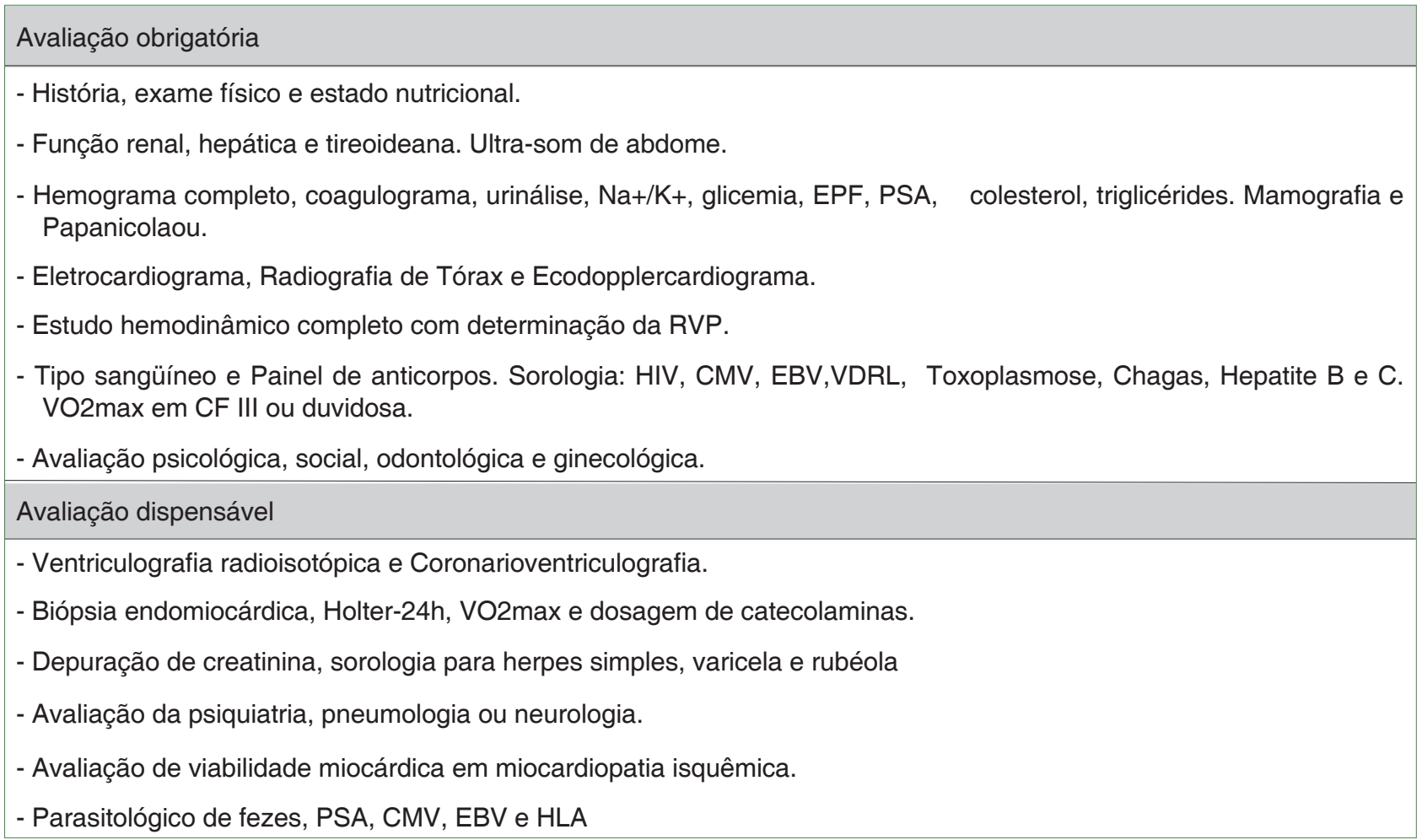

Fonte: Adaptado da II Diretriz sobre Transplante Cardíaco do GEIC. Sociedade Brasileira de Cardiologia - 2009.

Decidir qual o melhor momento de indicar o transplante cardíaco nem sempre é tarefa fácil, exigindo do médico assistente o real conhecimento dos fatores de risco que estão em jogo (não seria mais "científico" algo como: a serem analisados?). Aos pacientes portadores de arritmias ventriculares refratárias ou aos que requerem hospitalização com freqüência para medicação parenteral ou, ainda, àqueles que necessitam de suporte circulatório mecânico, não existem grandes controvérsias na indicação do transplante. Ao contrário dos demais nos quais a escolha dos receptores deve ser feita entre aqueles considerados críticos para comporem a lista de espera. Com a expansão das indicações para o transplante e a persistente escassez de doadores, torna-se obrigatória à adoção de critérios padronizados na seleção dos candidatos.

Durante a avaliação clínica, objetiva-se a confirmação da gravidade da cardiopatia; descartar a possibilidade de terapias opcionais, como revascularização do miocárdio ou substituição valvar; verificar a ausência de contra-indicações e estimar o prognóstico em curto prazo afim de que se possa auxiliar a inclusão do paciente em lista de espera. A maior discussão ocorre no estabelecimento do real momento da indicação para o transplante, nos pacientes críticos e que apresentam contra-indicações relativas ao procedimento. Uma vez indicado o transplante, devem-se excluir aquelas condições que aumentam a morbimortalidade no período pós-transplante (Quadro 2). 
Fiorelli AI, Oliveira Jr. J de L, Stolf NAG. Transplante cardíaco.

QUADRO 2. Fatores de risco no transplante cardíaco

- Idade.

- Enfermidades coexistentes de mau prognóstico.

- Miocardiopatia infiltrativa ou inflamatória.

- Hipertensão arterial pulmonar irreversível.

- Doenças pulmonares parenquimatosas irreversíveis.

- Tromboembolismo pulmonar agudo.

- Doença vascular cerebral ou periférica severa.

- Disfunção renal ou hepática irreversível.

- Úlcera péptica, diverticulose ou diverticulite ativa.

- Diabetes dependente de insulina com alterações viscerais.

- Obesidade ou osteoporose severa.

- Infecção ativa ou neoplasia coexistente.

- Instabilidade psicossocial, toxicomania ou ambas.

A idade limite tem importância relativa dado que os fatores biológicos referentes ao paciente exercem maior influência que a própria idade cronológica. As associações de fatores de morbimortalidade aumentam com a idade, porém, por si só exercem maior influência do que a própria idade do paciente. Todavia, o seu limite superior tem-se expandido progressivamente, aceitandose atualmente pacientes com até 70 anos e com ausência de outras contra-indicações relativas.

Em casos de miocardite ou miocardiopatia pós-parto, é possível a melhora da função ventricular, dificultando ainda mais a inclusão desses pacientes em lista. Deve-se ressaltar que a incidência de rejeição aguda pode aumentar em pacientes portadores de miocardite aguda, comprometendo a sobrevida após o transplante. As cardiopatias inflamatórias são uma contra-indicação relativa. As cardiopatias infiltrativas como a sarcoidose ou a amiloidose podem recorrer no coração transplantado, bem como as suas manifestações sistêmicas podem limitar a recuperação e a sobrevida em longo prazo ${ }^{10},{ }^{11}$.

A hipertensão pulmonar é considerada fator de risco no transplante de tal forma que pacientes com resistência acima de 2,5 unidades Wood apresentam mortalidade crescente, atingindo até valores críticos acima de 4 a 6 unidades Wood. A hipertensão pulmonar é fator alto de risco de falência do enxerto do pós-operatório imediato pela dificuldade que o ventrículo direito do enxerto pode apresentar na adaptação frente ao novo território vascular.

A reversibilidade da resistência vascular pulmonar é avaliada no pré-operatório pela reposta ao uso de vasodilatadores pulmonares, incluindo oxigênio, óxido nítrico, nitroprussiato de sódio, adenosina e prostaciclina. A função pulmonar deve ser avaliada adequadamente sem a presença de insuficiência cardíaca descompensada. A doença obstrutiva crônica com redução do volume expiratório forçado inferior a $50 \%$ do predito aumenta o risco de complicações respiratórias no pós-operatório.

A disfunção renal secundária ao baixo débito cardíaco deve ser diferenciada da insuficiência renal primária, pois os imunossupressores são hepatotóxicos e nefrotóxicos, e agravam disfunções pré-existentes. A etiologia e a reversibilidade da disfunção renal devem ser avaliadas antes de se contra-indicar o transplante cardíaco ou de se indicar o transplante renal associado.

Os pacientes portadores de colecistopatia crônica calculosa devem ser operados sempre que possível antes do transplante. A úlcera péptica em atividade é contra-indicação temporal ao transplante pelo risco de hemorragia, bem como a diverticulite ou colites recorrentes que aumentam o risco de peritonites fatais no pós-operatório. Os pacientes com diabete melito que dependem de insulina e que apresentam manifestações sistêmicas da doença, como arteriopatia, retinopatia, nefropatia e neuropatia, são excluídos.

A obesidade é um fator de risco ao transplante, quer pela dificuldade de se encontrar um doador compatível, quer pela maior incidência de complicações no pós-operatório. Tem-se considerado que peso corpóreo superior a $150 \%$ do ideal como alto fator de risco ao transplante, bem como ao desenvolvimento tardio da doença vascular do enxerto. A presença de arteriopatia periférica, da 
carótida ou ambas aumenta o risco intra-operatório de acidente vascular cerebral, associado aos efeitos aterogênicos dos corticóides que podem acelerar a progressão da própria aterosclerose.

As neoplasias cardíacas primárias são raras, ainda que existam publicações com êxito; a maioria dos acometidos morre precocemente por disseminação metastática e, portanto, a indicação do transplante deve ser cautelosa ${ }^{13,14}$. Os efeitos da imunossupressão sobre as neoplasias potencialmente curadas não são totalmente conhecidos; assim, temse recomendado de forma intuitiva excluir os pacientes com período inferior a cinco anos de evolução do tumor. A presença de neoplasias é contra-indicação absoluta para o transplante considerando-se o tempo de sobrevida imposto pela enfermidade e o risco de progressão do tumor pela imunossupressão.

A presença de instabilidade emocional, a baixa aderência à orientação médica, os usuários de drogas ilícitas, o baixo padrão social e a presença de dinâmica familiar inadequada são fatores de exclusão dos candidatos ao programa de transplante. plante

O melhor momento da indicação do trans-

O momento ideal para inscrever o candidato ao transplante em lista de espera constitui-se como um grande desafio. Por vezes, o real momento da indicação parece muito óbvio; todavia, cerca de 20 a $30 \%$ dos que ingressam na lista de espera apresentam sobrevida superior a um ano ou são retirados temporariamente pela melhora obtida com tratamento clínico agressivo e controlado. Essa situação ocorre como conseqüência da maior vigilância imposta aos pacientes que aguardam o transplante e da sua maior a obediência à terapêutica clínica aplicada.

Para se quantificar a capacidade funcional doas candidatos, tem-se aplicado o teste de caminhada por seis minutos, o exame ergométrico convencional ou

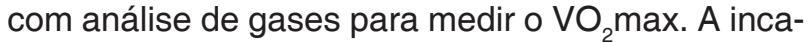
pacidade de caminhar 300 metros em seis minutos ou $\mathrm{VO}_{2}$ max inferior a $10 \mathrm{ml} / \mathrm{Kg} / \mathrm{min}$ são fatores de mau prognóstico e, portanto, são indicativos de inclusão dos pacientes em lista de espera.

Deve-se estar atento quanto à análise dos valores absolutos do $\mathrm{VO}_{2}$ max pelas possíveis limitações do método frente ao quadro clínico do paciente. $O$ seguimento clínico rigoroso dos pacientes oferece melhores informações que a análise do exame isolado. Os principais critérios adotados atualmente para indicar o momento de inclusão em lista de espera e prioridade não diferem daqueles apresentados na Conferência de Bethesda, em 1993 (Quadros 3 e $4)^{15}$.

QUADRO 3. Indicações para o transplante cardíaco

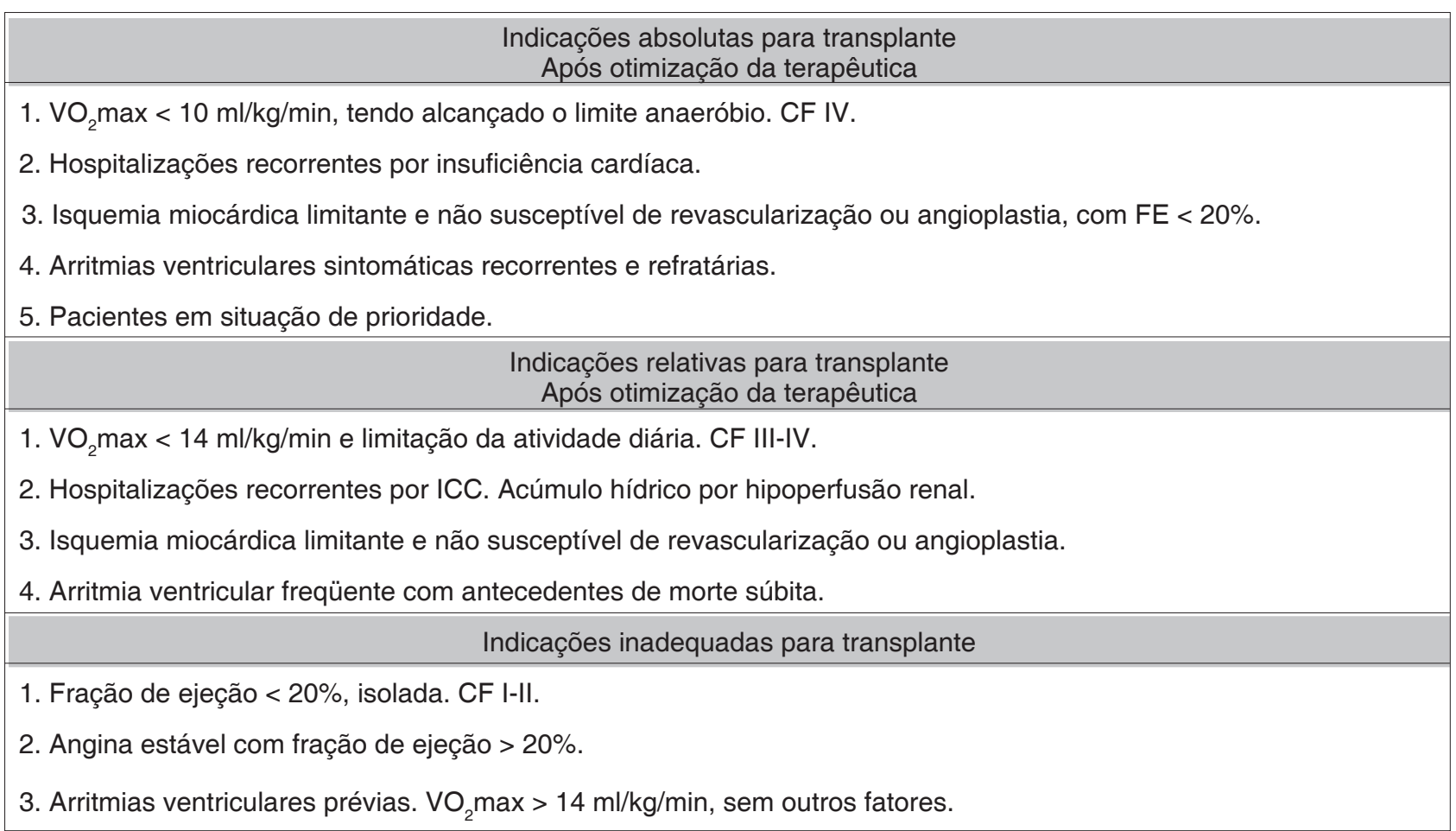


Fiorelli AI, Oliveira Jr. J de L, Stolf NAG. Transplante cardíaco.

QUADRO 4.Critérios de prioridade

1. Choque cardiogênico em uso de catecolaminas.

2. Choque cardiogênico em uso de assistência circulatória ou ventilação mecânica

3. Retransplante agudo por falência primária do enxerto.

4. Arritmias cardíacas malignas e incontroláveis.

\section{Controle dos candidatos até o transplante}

O candidato ao transplante exige cuidados constantes durante o período de espera em função da alta morbidade oferecida pela insuficiência cardíaca. O conceito de insuficiência cardíaca refratária ao tratamento clínico é variável e depende, entre outros fatores, da experiência da equipe em aplicar a terapêutica considerada maximizada, da aderência ao tratamento e da confiabilidade das informações fornecidas pelo paciente. O tratamento da insuficiência cardíaca deve obrigatoriamente incluir fármacos que retardem a progressão da doença, reduzam as reinternações, a mortalidade e os sintomas. No Quadro 5 encontram-se relacionados os principais medicamentos utilizados no tratamento, cuja orientação foi adaptada da II Diretriz sobre Transplante Cardíaco GEIC/SBC-2009 ${ }^{12}$.

QUADRO 5. Fármacos utilizadas no tratamento da insuficiência cardíaca

\section{Orientações aceitas}

1. IECA em doses máximas toleradas.

2. Se houver intolerância aos IECA usar Hidralazina-isossorbida.

3. Beta-bloqueadores se tolerados (carvedilol, bisoprolol, ou metoprolol) para CF III ou II.

4. Digoxina em pacientes com sintomas não tolerados ou em risco de hospitalização por ICC.

5. Digoxina nos casos de FA e resposta ventricular alta. Pode-se adicionar amiodarona.

6. Diurético se houver sinais/sintomas de congestão. Espironolactona

7. Anticoagulantes na FA ou eventos embólicos prévios ou trombos intracardíacos.

8. Amiodarona para arritmia sintomática ou taquicardia ventricular sustentada.

\section{Orientações discutíveis}

1. Digoxina para todos os pacientes sintomáticos não isquêmicos sem FA.

2. Vasodilatador adicional (nitratos) para pacientes sintomáticos.

3. Amiodarona para miocardiopatia dilatada idiopática.

4. Anticoagulante para aumento importante de ventrículo esquerdo.

5. Amlodipina para miocardiopatia dilatada com risco reduzido de edema agudo dos pulmões.

6. Bloqueador AT1 na intolerância ao IECA e principalmente em idosos.

7. Beta-bloquadores se tolerados (carvedilol, bisoprolol, ou metoprolol) para CF IV.

\section{Orientações não aceitas}

1. Bloqueadores de canal de cálcio (exceto amlodipina) na ausência de angina ou HAS.

2. Medicações para tratamento de arritmias ventriculares assintomáticas.

3. Uso intermitente de dobutamina em pacientes na ausência de instabilidade hemodinâmica.

4. Introdução de digital para assintomáticos ou com baixo risco de hospitalização.

5. Digoxina para miocardiopatia isquêmica sem FA com arritmia ventricular complexa.

AT1- Receptores da angiotensina 1, CF-Classe Funcional, FA-Fibrilação atrial, HAS- hipertensão arterial sistêmica, ICC-Insuficiência cardíaca congestiva e IECA-Inibidores da enzima de conversão da angiotensina. 


\section{Seleção do doador}

O sucesso do transplante depende, entre outros fatores, da qualidade do enxerto, devendo-se assegurar que ele seja capaz de manter condições hemodinâmicas adequadas ao receptor após o implante e estar isento de transmitir doenças infecciosas ou tumorais. Para se obter órgãos em condições adequadas, é necessário que o doador continue sendo tratado como um paciente crítico mesmo após a confirmação da morte encefálica.

No Brasil, por meio da Resolução N 1346 de 08/08/91, o Conselho Federal de Medicina publicou os critérios adotados no diagnóstico da morte encefálica, que em essência não diferem daqueles aceitos universalmente. Muito embora se tenha ampliado o investimento para aumentar o número de doadores de órgãos para transplante, a qualidade dos órgãos deixa ainda a desejar, sendo esse o maior fator de recusa dos órgãos doados.

A radiografia de tórax, eletrocardiograma e ecocardiograma são exames fundamentais na avaliação dos doadores de coração, e, em situações especiais, o cateterismo cardíaco. $\mathrm{Na}$ investigação laboratorial inclui-se a sorologia para sífilis, hepatite, doença de Chagas e SIDA. As determinações das sorologias para citomegalovírus e toxoplasmose apresentam valor no seguimento clínico do paciente.

No diagnóstico clínico da morte encefálica, é obrigatório o conhecimento da causa do coma, para excluir a possibilidade de intoxicações metabólicas ou exógenas. Os seguintes parâmetros neurológicos devem ser observados: coma profundo aperceptivo e arreativo; apnéia; midríase paralítica; ausência de reflexos óculo-motor e córneo-palpebral. Para confirmação do diagnóstico clínico da morte encefálica, os parâmetros acima descritos devem permanecer inalterados por período superior a seis horas. A sua documentação laboratorial é obrigatória e deve ser realizada por um dos métodos que confirme a ausência de fluxo cerebral, como a arteriografia, a cintilografia ou o ecodopller transcraniano, ou ainda que comprove a inatividade cerebral, como o eletroencefalograma ou o potencial evocado. A Figura 1 apresenta de forma esquemática as principais manifestações evidenciadas na fisiopatologia da morte encefálica, independente da sua etiologia.

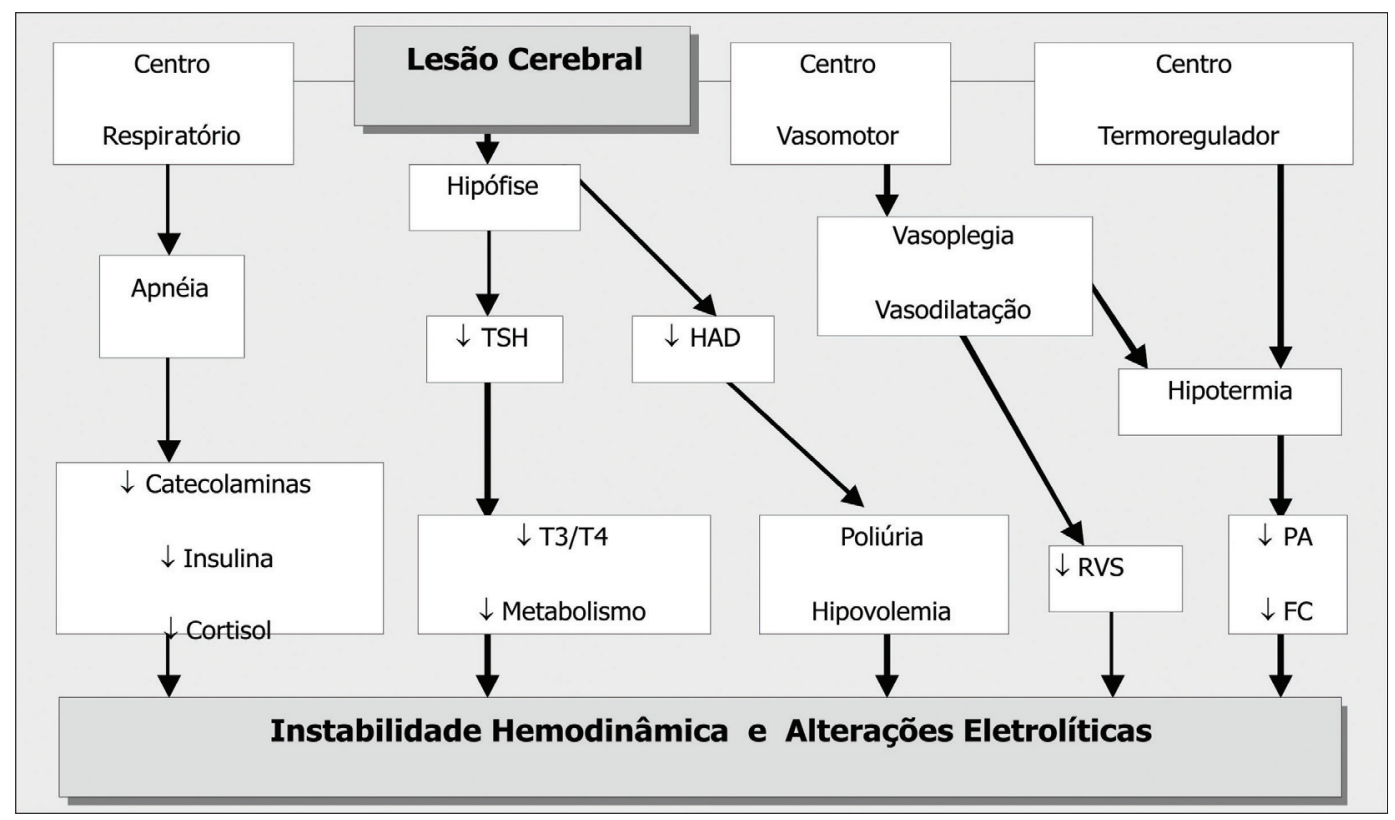

FIGURA 1. Fisiopatologia da morte encefálica

Os critérios adotados na seleção dos doadores de coração são mais rígidos que aqueles aplicados aos demais órgãos, podendo diferir entre as equipes ou pelas condições clínicas do receptor. A carência de doadores tem motivado a extensão dos limites da faixa etária até 50-55 anos: acima dos 40 anos para os homens e acima dos 45 anos para as mulheres, é recomendado o emprego da cinecoronariografia, tendo em vista o risco de coronariopatia. Essa orientação adquire maior importância nos doadores 
Fiorelli AI, Oliveira Jr. J de L, Stolf NAG. Transplante cardíaco.

com antecedentes de tabagismo, diabete melito, hipertensão arterial ou vítimas de acidente vascular cerebral.

A presença de hipotensão arterial ou o uso de drogas vasoativas em altas doses, por período superior a 12-24 horas, constituem-se fatores de risco para o transplante e são, muitas vezes, responsáveis pelo aparecimento de disfunção do enxerto no pósoperatório. A parada cardíaca por si só não é critério de exclusão do órgão, desde que após o evento o mesmo readquira condições hemodinâmicas estáveis. O peso corpóreo do doador não deve ser inferior a $20 \%$ do peso do receptor, principalmente quando o receptor apresenta resistência pulmonar elevada, preferindo-se, então, doadores de maior porte físico.

A procura de órgãos à distância é uma realidade e visa aumentar o número de transplantes. O método foi utilizado em coração pioneiramente pelo grupo de Stanford e corresponde a cerca de $80 \%$ dos transplantes na experiência internacional. O tempo de isquemia do coração não deve ultrapassar o limite de 4 a 6 horas para que o transplante seja realizado com segurança.

A histocompatibilidade entre o doador e o receptor é avaliada pela compatibilidade obrigatória entre os grupos sangüíneos ABO e pela obtenção do resultado negativo da prova cruzada de linfócitos do doador com o soro do receptor (crossmatch). Nos receptores cuja reatividade linfocitária é inferior a $10 \%$, frente a um painel de linfócitos, não há obrigatoriedade de se aguardar o resultado da prova cruzada para se iniciar a operação. O fator Rh não é valorizado no caso dos transplantes de órgãos e a compatibilidade HLA tem apenas valor retrospectivo.

\section{TÉCNICA OPERATÓRIA}

\section{Operação no doador}

A toracolaparotomia mediana é a via de acesso para exposição dos órgãos intracavitários. Na avaliação macroscópica do coração deve-se estar atento à presença de hematomas ou anormalidades na contração ventricular. O desempenho do ventrículo direito pode ser avaliado pela compressão delicada do tronco pulmonar ou aumentandose o retorno venoso, colocando-se o doador em posição de Trendelemburg. A palpação das artérias coronárias e aorta auxiliam na identificação de placas de ateromas ou frêmitos, indicativos de doença coronária ou valvar.
Administra-se heparina na dose de $400 \mathrm{UI} / \mathrm{Kg}$ de peso corpóreo, por via endovenosa, antes do início da retirada dos órgãos. A aorta é ocluída próximo à emergência do tronco braquicefálico, seguindose a infusão de solução cardioplégica cristalóide a $4^{\circ} \mathrm{C}$ e a infusão de solução salina gelada no saco pericárdico. Mantêm-se as câmaras cardíacas descomprimidas, evitando-se suas distensões. Após a remoção, o coração é imediatamente transportado em sacos plásticos estéreis e imerso em solução salina gelada a $4^{\circ} \mathrm{C}$. No preparo final do coração, os orifícios das veias pulmonares podem ser unidos ou não, em função da técnica adotado no implante.

\section{Operação no receptor}

Cuidados adicionais devem ser adotados com os receptores de coração pela maior labilidade hemodinâmica e pela possibilidade de apresentarem parada cardíaca durante a indução anestésica. A monitorização hemodinâmica invasiva somente tem início no receptor após a realização da toracotomia no doador, tendo sido garantida a viabilidade do coração para o transplante. A via de acesso ao coração é a toracotomia longitudinal com esternotomia seguindo-se a pericardiotomia longitudinal, permitindo assim ampla exposição do órgão para a instalação da circulação extracorpórea de forma habitual.

Na técnica clássica, o coração nativo é retirado pela excisão dos seus ventrículos, incluindo as valvas cardíacas, com secção nos planos atrioventricular e ventrículo-arterial (Figura 2). O tamanho dos átrios remanescentes é ajustado para receberem o enxerto. Inicia-se o implante do coração doador pela anastomose do átrio esquerdo em direção ao septo interatrial, finalizando-se com o fechamento do átrio direito. Em algumas situações, as dimensões dos átrios do receptor são excessivamente grandes e dificultam o ajuste perfeito com os átrios do doador. Nesses casos, recomenda-se para o átrio direito a sua redução pelo fechamento do seu ângulo inferior junto à desembocadura da veia cava inferior. A terceira anastomose a ser realizada é a do tronco pulmonar, cujos tamanhos e diâmetros devem estar perfeitamente compatíveis, tendo-se como ponto de orientação o alinhamento de uma das comissuras pulmonares. A anastomose da aorta obedece aos mesmos princípios descritos para o tronco pulmonar, iniciando-se pela parede posterior em direção ao ponto médio da parede anterior. Antes da retirada da pinça da aorta devem-se realizar as manobras habituais para a retirada de ar das cavidades cardíacas. 


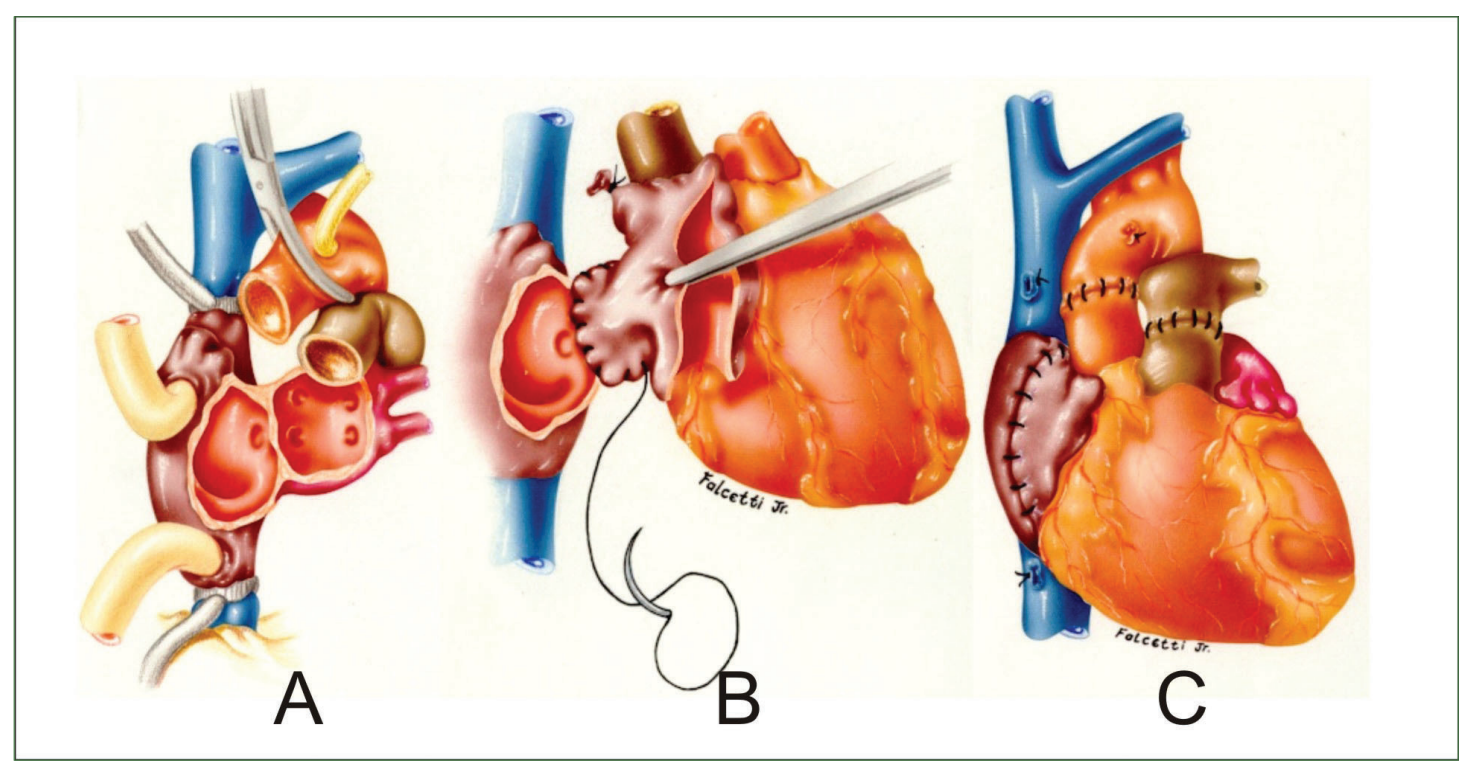

FIGURA 2. Transplante pela técnica clássica. A - Retirada do coração nativo. B - Anastomose dos átrios esquerdos. C Aspecto final do implante do coração doador

Atualmente, tem-se dado ênfase à técnica do transplante ortotópico total, descrita inicialmente por Yacoub et al. ${ }^{16}$, em 1989, e posteriormente apresentada por Dreyfus et al. ${ }^{17}$, em 1991 (Figura 2). A razão básica do emprego dessa técnica apóia-se na hipótese de que as anastomoses diretas das veias pulmonares e das veias cavas mantêm intactos os átrios do doador oferecendo maior estabilidade elétrica e maior capacidade de bomba. A distorção das câmaras cardíacas é menor e, portanto, haveria menor incidência de insuficiência valvar tricúspide e mitral no pós-operatório; todavia, os resultados elínieos ainda são controversos e requerem maior experiência clinica.

Para reduzir a incidência de insuficiência tricúspide tardia, temse sugerido a realização profilática da anuloplastia valvar no coração doador (Figura 3A) ${ }^{18,19}$. Quanto à anastomose do átrio esquerdo pela técnica bicaval, essa pode ser realizada com anastomose uni-atrial ou bipulmonar, pois se acredita essa última apresenta distorção menor (Figura 3B).

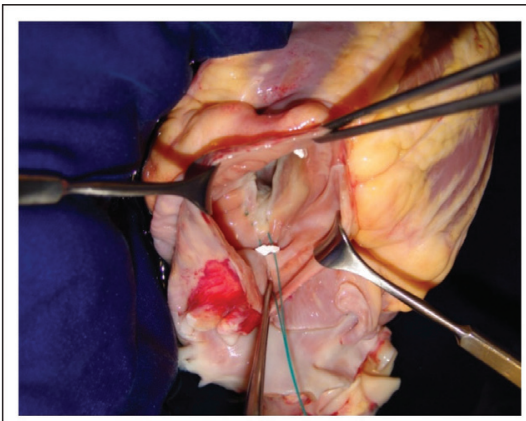

A

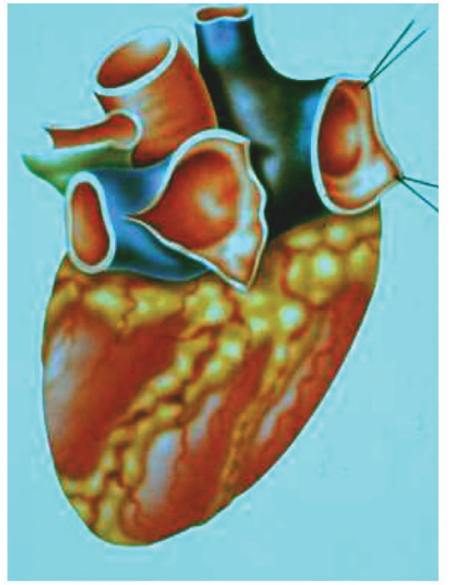

C

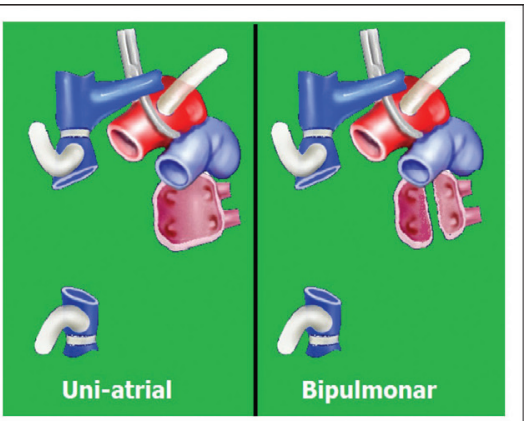

B

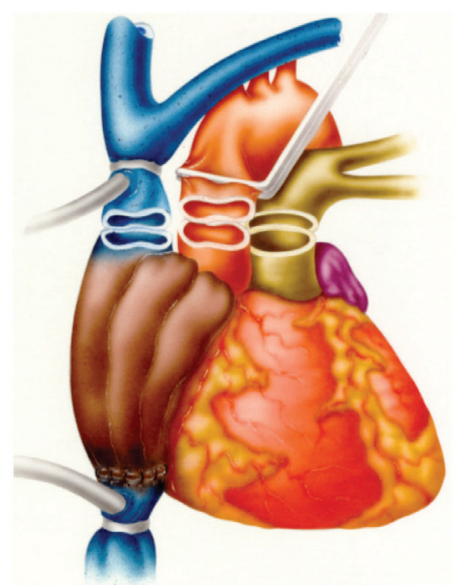

D
FIGURA 3. A - Realização da anuloplastia profilática no coração doador. B - Preparo do átrio esquerdo para anastomose uni-atrial ou bipulmonar com implante do enxerto pela técnica bicaval. C - Preparo do coração doador. D - Aspecto final do implante pela técnica bicaval 
Fiorelli AI, Oliveira Jr. J de L, Stolf NAG. Transplante cardíaco.

As dificuldades no retransplante são aquelas próprias das reoperações cardíacas, nas quais o sangramento é o fator de maior risco. As dissecções devem ser feitas de forma cuidadosa e as cânulas para instalação da circulação extracorpórea da forma habitual. O acesso ao coração por toracotomia esquerda com a colocação das cânulas em ventrículo direito para drenagem venosa e a perfusão pela aorta ascendente constituem uma alternativa interessante. Após a retirada do coração nativo, com hipotermia profunda e parada circulatória, as cânulas de drenagem são mais facilmente introduzidas nas veias cavas.

\section{Transplante cardíaco heterotópico}

O transplante heterotópico foi uma das primeiras modalidades de operações experimentais, iniciada por Carrel e Guthrie ${ }^{1}$ e, posteriormente, por Demikhow. Todavia, foi aplicado pioneiramente na prática clínica por Barnard, em 1974, sendo inicialmente empregado como suporte ao ventrículo esquerdo e, mais tarde, como assistência biventricular. O transplante heterotópico não é o método de eleição, dado que suas indicações tem sido restritas e poucos centros apresentam larga experiência com esse procedimento. As indicações para o transplante heterotópico são basicamente as mesmas adotadas no transplante ortotópico. Todavia, o transplante heterotópico tem sido reservado para situações especiais, tais como:

- receptor com resistência vascular pulmonar elevada, acima de 6 a $8 \mathrm{U}$ Wood;

- quando o receptor encontra-se em estado crítico e existe grande desproporção com o peso do doador;

- quando a viabilidade do coração doador pode estar comprometida por tempo de anóxia prolongado ou proteção miocárdica comprometida;

- quando é possível a recuperação do coração receptor, como nas miocardites ou após cirurgia cardíaca.

A insuficiência valvar severa ou presença de prótese cardíaca são critérios específicos de exclusão para o transplante heterotópico, devido aos riscos de endocardite ou tromboembolismo no pós-operatório. O transplante heterotópico não modifica substancialmente a função do coração nativo, e o débito cardíaco de cada um deles depende fundamentalmente da sua própria contratilidade, distensibilidade, da pré e pós-carga sistêmica. A eficiência hemodinâmica desse tipo de transplante pode ser observada pela melhora clínica dos pacientes, tolerando arritmias e mesmo parada do seu próprio coração. A Figura 4 apresenta a representação da técnica no transplante heterotópico.

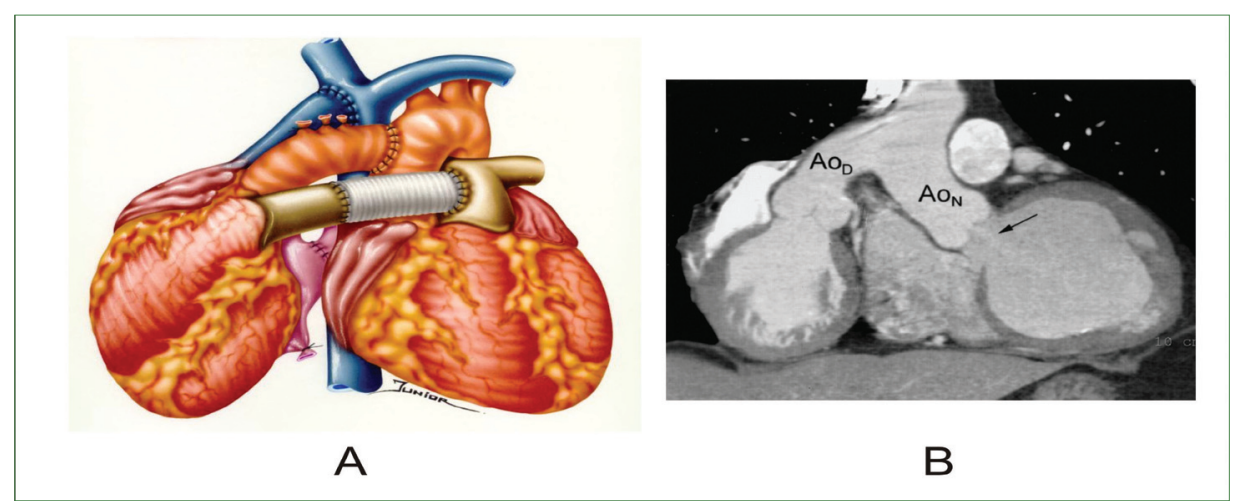

FIGURA 4. A - No transplante heterotópico o coração doador fica à direita. Nota-se a interposição do enxerto tubular para unir o tronco pulmonar do doador ao do receptor. B - Angioressonância onde se pode identificar a união da aorta do doador (AoD) com a aorta nativa (AoN)

\section{Evolução pós-operatória}

As complicações mecânicas do enxerto predominam na fase imediata à operação e ocorrem em conseqüência das injúrias sofridas pelo coração doador, da sua adaptação no sistema vascular do receptor, do ato operatório propriamente dito ou pela associação destes fatores. As complicações que ocorrem mais tardiamente estão intimamente ligadas aos efeitos colaterais da imunossupressão, dos fenômenos imunológicos ou de ambos.

A reatividade vascular pulmonar do receptor desempenha papel decisivo no comportamento imediato do enxerto após o transplante, pois, na vigência de resistência vascular pulmonar elevada, o ventrículo direito do enxerto é a câmara que sofre 
maior impacto. A sua falência reduz o débito cardíaco e predispõe à disfunção do ventrículo esquerdo, colocando em risco a perda total do enxerto. A recuperação do coração desenervado geralmente ocorre em uma semana e durante esse período o uso de fármacos inotrópicos positivos (dopamina, dobutamina ou isoprenalina) e de vasodilatadores (nitroprussiato, nitroglicerina ou prostanglandina) constitui-se como um valioso recurso para auxiliar na fase de adaptação ${ }^{20}$.

A disfunção do nó sinusal é a principal causa imediata de bradiarritmia, seguida de anomalias da condução atrioventricular. São, geralmente, reversíveis e decorrentes da anóxia do enxerto, do traumatismo cirúrgico ou de anomalias da artéria do nó sinusal. A estimulação cardíaca artificial temporária deve ser empregada quando a bradicardia é mais acentuada; porém, na sua persistência, indica-se o implante de marcapasso definitivo. Em nossa experiência, $12,3 \%$ dos pacientes operados necessitaram de estimulação cardíaca temporária, e $3,5 \%$ de definitiva ${ }^{21}$.

\section{Função renal e imunossupressão}

A ciclosporina promove a vasoconstrição da arteríola eferente, que associada à sua ação tóxica direta nos túbulos renais determina a perda de função do néfron e predispõe ao aparecimento de hipertensão arterial. Todavia, a fisiopatologia da nefropatia no transplante é controversa e multifatorial, sendo inicialmente reversível e dosedependente, tornando-se mais tarde irreversível. Com a ciclosporina, a nefrotoxicidade é inevitável, podendo-se minimizar esse efeito com a redução da imunossupressão. A elevação progressiva dos níveis de creatinina pode ser observada já a partir do sexto mês de evolução, acompanhada de uremia desproporcionada, hipercalcemia, hiperuricemia e queda de excreção urinária de sódio.

O esquema tríplice de imunossupressão é composto pela associação de ciclosporina, corticóide e azatioprina, estando presente nos protocolos atuais para minimizar os efeitos de cada fármaco isoladamente. A ciclosporina somente é introduzida no $2^{\circ}$ ou $3^{\circ}$ dia de pós-operatório por via oral na dose de 3 a $5 \mathrm{mg} / \mathrm{Kg}$ de peso corpóreo, fracionada em duas tomadas, desde que a função renal e o estado hemodinâmico estejam preservados. Se a realimentação não puder ocorrer, então, esse fármaco é administrado por via endovenosa na dose diária de $1 \mathrm{mg} / \mathrm{Kg}$ de peso corpóreo, em oito horas. Na presença de qualquer manifestação de disfunção renal, oligúria ou aumento de creatinina, a ciclosporina-A deve ser reduzida ou suspensa temporariamente. Nesta última situação, tem-se associado a imunoglobulina antitimocitária (ATG) ou antilinfocitária (ALG) na dose de $10 \mathrm{mg} / \mathrm{Kg}$ de peso corpóreo, por período de até duas semanas, ajustando-se a dose em função do número de linfócitos. Os anticorpos monoclonais contra linfócitos T3 (OKT3) também podem ser utilizados com benefícios controversos.

Novos imunossupressores têm sido incorporados no arsenal terapêutico com vantagens adicionais. O micofenolato em substituição à azatioprina, o tracolimus, à ciclosporina, os inibidores da TOR (target of rapamicina) e outros. No desenvolvimento de novos imunossupressores visa-se a aliar propriedades antiproliferativas com o intuito de coibir a doença vascular do enxerto.

O esquema de imunossupressão pode ser modificado em função da evolução clínica, nas rejeições, infecções, hiperglicemia persistente e nas neoplasias. Durante os períodos de rejeição graves utiliza-se a pulsoterapia endovenosa com $1 \mathrm{~g}$ de metilprednisolona durante três dias, podendo ser repetida caso não ocorra a sua regressão. Nos casos de difícil regressão, utiliza-se um dos imunossupressores linfocíticos citados (ATG ou OKT3), e nos casos recorrentes tem-se associado o metotrexate com resultados satisfatórios.

\section{Controle de rejeição}

A rejeição aguda mediada pela ativação ou formação de linfócitos é denominada de rejeição celular. Quando ocorre pela participação de anticorpos pré-formados, recebe a designação de rejeição humoral, cuja ocorrência é menos freqüente. A distinção entre elas nem sempre é evidente, podendo coexistir ambos os mecanismos no mesmo processo de rejeição.

A rejeição hiperaguda é uma forma grave de rejeição humoral e ocorre em curto espaço de tempo, determinando a destruição e a falência imediata do enxerto. A resposta é basicamente humoral e os anticorpos pré-formados reagem rapidamente contra antígenos do doador. Esses anticorpos resultam usualmente da exposição prévia aos antígenos por gravidez ou transfusão sangüínea. Deve-se ressaltar que esse tipo de rejeição pode ocorrer mesmo na ausência de incompatibilidade $\mathrm{ABO}$ ou de anticorpos anti-HLA, pois é mediado por anticorpos citotóxicos dirigidos contra o sistema endotelial. Sua incidência pode ser reduzida mediante o estudo prévio do grau de sensibilização alogênica do receptor denominado de painel de linfócitos e pela prova cruzada específica (cross-match), especialmente nos pacientes sensibilizados (painel $>10 \%$ ). 
Fiorelli AI, Oliveira Jr. J de L, Stolf NAG. Transplante cardíaco.

Os episódios de rejeição aguda são fundamentalmente celulares e caracterizados por infiltração linfóide no coração, aparecendo em geral a partir da primeira semana após o transplante. A expressão anatomopatológica é caracterizada pela quantidade de infiltrado linfocitário, presença de miocitólise e pelo tecido cicatricial fibroso.

Os principais fatores de risco de rejeição são: receptor jovem do sexo feminino, grau de incompatibilidade HLA, coração doador proveniente de mulher jovem, doador de grupo sangüíneo não-O, painel de linfócitos superior a $10 \%$, prova cruzada positiva e infecção por citomegalovírus. A ciclosporina não reduziu a incidência de rejeição aguda, porém os episódios tornaram-se mais benignos com pouca repercussão hemodinâmica e de mais fácil controle.

A biópsia endomiocárdica do ventrículo direito é o método padrão do diagnóstico de rejeição. Em nossa instituição, foram desenvolvidos protocolos especiais de avaliação ecocardiográfica e de cintilografia com Gálio-67, esse merecendo menção especial pela sua alta sensibilidade e especificidade. Em crianças, especialmente, pelas dificuldades técnicas do uso seriado das biópsias, o controle da rejeição tem-se apoiado no estudo ecocardiográfico.

\section{Infecção}

A antibioticoprofilaxia tem sido proposta para infecções específicas; assim, nos primeiros meses após o tratamento da rejeição aguda, a pirimetamina e trimetropim-sulfametoxazol têm sido empregadas na prevenção da toxoplasmose e da pneumocistose, respectivamente. Nos casos de infecção por citomegalovírus, a profilaxia com aciclovir, ganciclovir ou imunoglobulina é controversa, apesar dessa infecção estar associada à alta morbidade e mortalidade. Todavia, quando o doador apresenta sorologia positiva para o citomegalovírus e o receptor, negativa, a profilaxia está indicada, considerandose o risco de 25 a $45 \%$ do aparecimento da forma clínica de infecção. Em estudo multicêntrico Transplant Cardiologists Reserch Database -, no qual foram analisadas somente as infecções graves que necessitaram de terapia oral ou endovenosa, observou-se incidência de 0,5 episódios de infecção/ paciente ano, após o transplante cardíaco. Verificouse também que $68 \%$ dos pacientes não apresentaram infecção, $21 \%$ tiveram um episódio de infecção e $11 \%$ deles apresentaram mais de um episódio de infecção ${ }^{22}$.

A distribuição da incidência dos processos infecciosos acompanha a curva de rejeição, sendo mais freqüente e mais grave nos primeiros meses após o transplante, pois nessa fase a imunossupressão é mais intensa. $\mathrm{Na}$ fase imediata ao transplantelante predominam as infecções hospitalares, associadas à contaminação no intra-operatório em relação à pré-operatória, ocasionadas por estafilococos ou por gram negativos. Posteriormente, predominam as infecções por oportunistas, como o citomegalovírus, pneumocístis e fungos.

As infecções da ferida operatória ocorrem em pouco mais de $7 \%$ dos pacientes, porém podem cursar com alta mortalidade. A incidência de mediastinite é da ordem de $0,5 \%$ a $5,0 \%$ em cirurgia cardíaca convencional e pode atingir até $8 \%$ após o transplante cardíaco. Na nossa experiência, essa incidência é de 5,6\%, e o Staphylococcus aureus foi agente etiológico identificado em $66,7 \%$ dos pacientes na secreção da incisão, do mediastino ou ambos. $O$ Staphylococcus epidermidis ocorreu em $16,7 \%$, o Enterococcus faecalis em $8,3 \%$, e em $8,7 \%$ dos pacientes o agente etiológico não foi determinado. Em 16,7\% dos pacientes, optou-se pela manutenção da ferida cirúrgica aberta e com curativos diários, sendo que a ressecção total do esterno foi realizada em $8,3 \%$ dos pacientes ${ }^{8}$.

\section{Doença vascular do enxerto}

A doença vascular do enxerto é o resultado final da agressão imunológica crônica à íntima do vaso, predispondo ao aparecimento da isquemia miocárdica silenciosa, que ao lado da fibrose miocárdica, causam disfunções em longo prazo no coração transplantado. A patogênese e os fatores coadjuvantes que atuam no seu aparecimento continuam incertos, discutindose a participação da agregação plaquetária sobre as lesões endoteliais e a ação de anticorpos citotóxicos. Recentemente, tem-se discutido a participação da infecção por citomegalovírus e as alterações dos lipídios como fatores coadjuvantes ao aparecimento dessa complicação após o transplante. Nas formas mais graves, a manifestação clínica usual é o infarto do miocárdio seguido da disfunção ventricular ou morte súbita. $\mathrm{O}$ emprego da cinecoronariografia é o exame que confirma diagnóstico da lesão coronária, uma vez que os exames não invasivos apresentam resultados com baixa sensibilidade.

Na nossa série, os resultados têm mostrado que a incidência dessa complicação ocorre no primeiro ano de evolução em $13,6 \%$ dos pacientes, aumentando progressivamente até $44,4 \%$ no quinto ano ${ }^{24,25}$. Esses dados são comparáveis aos reportados na literatura, e a introdução da ciclosporina na imunossupressão não parece ter modificado a sua incidência. As avaliações dos achados cinecoronariográficos no transplante cardíaco confirmaram que as obstruções 
coronárias acometem geralmente os segmentos distais. A ocorrência de lesões críticas isoladas é muito rara no transplante, diminuindo as chances de angioplastia.

Em83,3\% das necropsias, em nossa experiência, observaram-se sinais de obstrução coronária, enquanto a angiografia detectou apenas em $33,3 \%$, confirmando que a incidência da lesão coronária é superior àquela observada em estudos cineangiográficos (Figura 5). Por outro lado, estudos morfológicos têm demonstrado que grande número de disfunções ventriculares parece ser decorrente de alterações isquêmicas causadas por oclusões dos pequenos vasos intramurais e que não são evidenciados na angiografia.

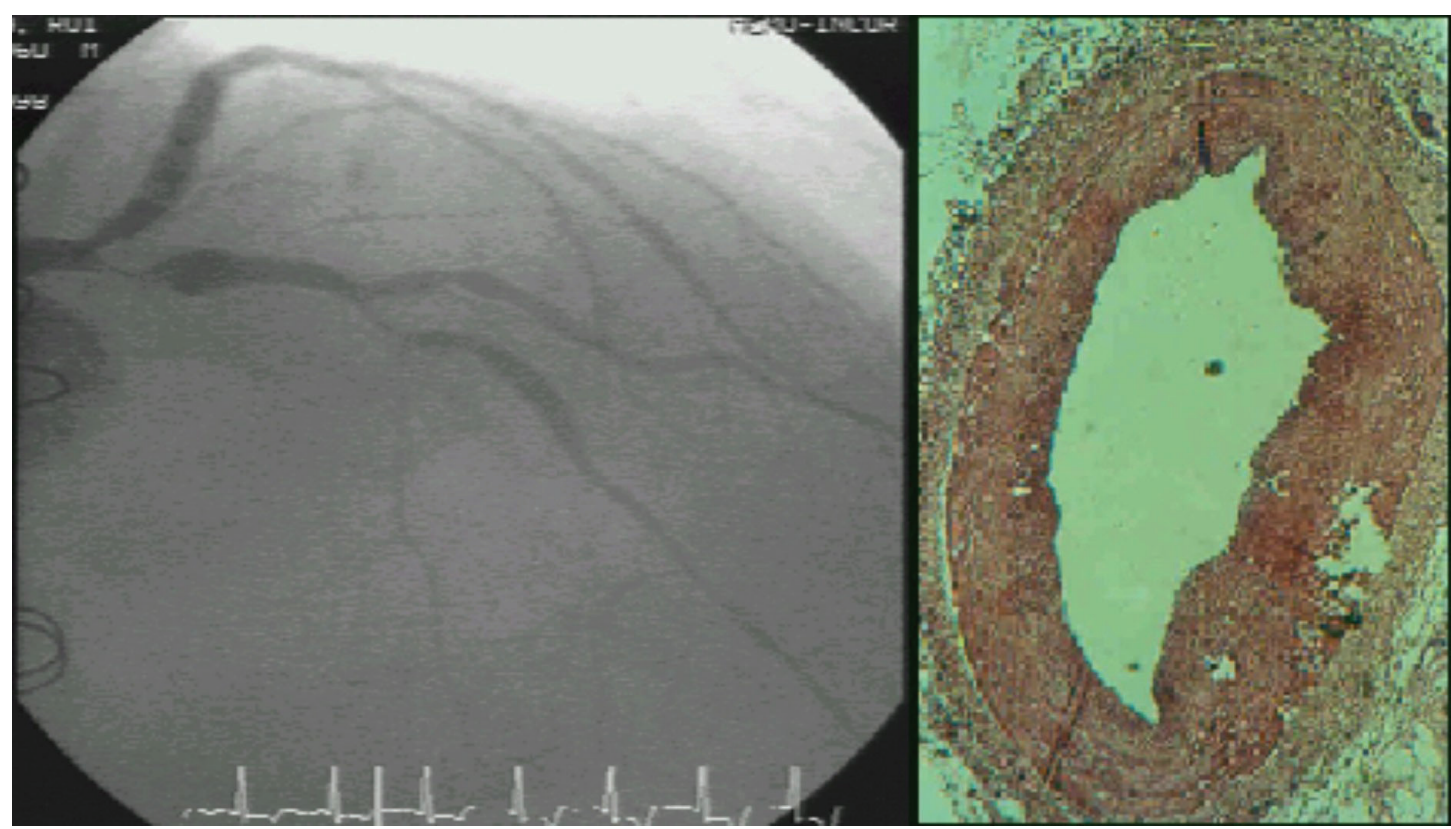

FIGURA 5. Cinecoronariografia demonstra a presença de doença vascular do enxerto com lesões graves nas artérias coronárias. Ao lado pode-se identificar o intenso grau de proliferação da média produzindo redução da luz do vaso

\section{Alterações gastrintestinais}

A pancreatite aguda após o transplante ocorre com freqüência variável entre $2 \%$ e $18 \%$ e, quando severa, apresenta alta morbidade e mortalidade. O seu aparecimento pode estar ligado a diferentes fatores, destacando-se a hipoperfusão esplênica, doença biliar, pancreática prévia, infecção por citomegalovírus ou pela ação das drogas imunossupressoras, em especial a ciclosporina e a azatioprina.

A hepatotoxicidade da imunossupressão, em especial pela azatioprina ou ciclosporina-A, pode ser responsável pela elevação transitória inicial das enzimas hepáticas e das bilirrubinas. Essas alterações acentuam-se quando, no pré-operatório, há congestão passiva crônica como conseqüência do baixo débito. A ciclosporina-A predispõe à estase biliar, com elevação em geral da bilirrubina direta e da fosfatase alcalina. Em nossa série, $15,9 \%$ dos pacientes desenvolveram colecistite.

A gastrite e a úlcera péptica podem aparecer ou ser reativadas pelo uso do corticóide ou pelas infecções, em especial, pelo citomegalovírus. Temse encontrado correlação estreita entre o tempo de aparecimento dessas complicações abdominais e o uso da pulsoterapia. A profilaxia com bloqueadores H2 e antiácidos, particularmente nos pacientes de risco, reduzem a incidência destas complicações. Deve-se salientar que as úlceras pépticas, ao lado dos divertículos dos cólons, podem perfurar e determinar quadro clínico grave de peritonite, muitas vezes atenuado pela inibição da resposta inflamatória.

As infecções ocasionadas por Candida Albicans, herpes simples e fungos podem acometer o trato digestivo alto produzindo disfagia em graus variáveis, cujo diagnóstico deve ser confirmado pela endoscopia com biópsia para a instalação de terapêutica adequada. cardíaco

Limitações e perspectivas do transplante

A despeito dos grandes benefícios que o transplante propicia, em termos de melhora da 
Fiorelli AI, Oliveira Jr. J de L, Stolf NAG. Transplante cardíaco.

perspectiva e qualidade de vida, existem três importantes limitações ${ }^{27,28}$ :

- contra-indicações médicas e psicossociais;
- falta de doadores e

- efeitos colaterais dos agentes imunossupressores.

Fiorelli Al, Oliveira Jr. J de L, Stolf NAG. Cardiac transplantation. Rev Med (São Paulo). 2009 jul.-set.;88(3) ed. especial:123-37.

ABSTRACT: The incidence of heart failure has increased in the recent years due to increased longevity of population, advances in treatment of acute myocardial infarction with the use of thrombolytics and angioplasty, the expansion of cardiac procedures and improvement in diagnosis of the syndrome. With recently incorporated changes in pharmacological treatment there was a significant improvement in patient survival. However, the development of cardiomyopathy to terminal forms is inexorable by the characteristics of the disease and in these situations the heart transplantation may be the only effective alternative. Heart transplantation is the only effective way to restore hemodynamic function of the patient, but has limitations of different orders and do not apply to all candidates. The shortage of viable organs is one of the biggest factors hindering the development of transplant, especially in those organs that are more susceptible to injuries from the shock and ischemia. In Brazil, despite the great progress made in the law of organ transplants, there is still a lack of an effective health policy aimed at promoting the capture and maintenance of appropriate donor organs. Only then this situation can be reversed. Modern immunosuppression works well in control of rejection episodes, but requires greater specificity. Side effects are still a concern and require the strict control of patients in long term. The quality of donor organs and the serious illness of the applicants who come to transplant centers are the main factors responsible for unsatisfactory results in the immediate postoperative period of heart transplantation. The present study aims to present a review of the principal stages that occur in the heart transplantation.

KEY WORDS: Heart failure. Heart transplantation. Immunosuppression.

\section{REFERÊNCIAS}

1. Carrel A, Guthrie CC. The transplantion of veins and organs. Am Med. 1905;10:1101.

2. Lower RR, Shumway NE. Studies on orthotopic transplantation of the canine heart. Surg Forum. 1960;11:18.

3. Hardy JD, Chaves CM, Kurrus FD, et al. Heart transplantation in man: developmental studies and report of a case. JAMA. 1964;188:1132.

4. Barnard C. The operation. A human cardiac transplantation: An interim report of the successful operation performed at Groote Schuur Hospital Cape Town. S Afr Med J. 1967;41:1271.

5. Zerbini, E.J.;Decourt, L.V. Experience on three cases of human heart transplantation. In: Symposium Mondial Deuxiemé Level Heart Transplantation. Annals of the 2nd. World Symposium, Quebec, 1969. p.179.

6. Grattan MT, Moreno-Cabral CE, Starnes VA, et al. Eight-year results of cyclosporine treated patients with cardiac transplants. J Thorac Cardiovasc Surg. 1990;99:500-9.

7. Hosenpud JD, Bennett LE, Keck BM, Novick RJ. The Registry of the International Society for Heart and Lung
Transplantation: Eighteenth Official Report-2001. J Heart Lung Transplant. 2008;27:937-83.

8. I Diretriz da Sociedade Brasileira de Cardiologia para Transplante Cardíaco. Arq Bras Cardiol. 1999:73(supl. 5).

9. Mancini DM, Eisen H, Kussmaul W, et al. Value of peak exercise oxigen consumption for optimal timing of cardiac transplantation in ambulatory patients with heart failure. Circulation. 1991;83(3):778.

10. Shumway NE. Recent advances in cardiac transplantation. Transplant Proc. 1983;15:1221.

11. Hertz MI, Aurora P, Christie JD, Dobbels F, Edwards LB, Kirk R, et al. Registry of the International Society for Heart and Lung Transplantation: a quarter century of thoracic transplantation. J Heart Lung Transplant. 2008;27:937-42.

12. II Diretriz sobre Transplante Cardíaco do GEIC Sociedade Brasileira de Cardiologia - 2009. [No prelo].

13. Miller LW. Listing criteria for cardiac transplantation. Results of an American Society of Transplant Physicians-National Institutes of Health Conference. 
Transplantation. 1998;66:947-51.

14. Costanzo MR, Augustine S, Bourge R, et al. Selection and treatment of candidates for heart transplantation. A statement for health professionals from the Committee on Heart Failure and Cardiac Transplantation Council on Clinical Cardiology, American Heart Association. Circulation. 1995;92:3593-612.

15. Mudge GH, Goldstein S, Addonizio LJ, et al. Twentyfourth Bethesda Conference: Cardiac Transplantation: Task Force 3: recipient guidelines/prioritization. J Am Coll Cardiol. 1993;22:21-31.

16. Yacoub MH, Radley-Smith R. Heart transplantation in infants and children. Semin Thorac Cardiovasc Surg. 1990;2:206.

17. Dreyfus G, Jebara V, Mihaileanu S, Carpentier AF. Total ortothopic heart transplantation: an the standart technique. Ann Thorac Surg. 1991;52:1181.

18. Jeevanandam V, Russell $H$, Mather P, Furukawa S, Anderson A, Grzywacz F, Raman. A oneyear comparison of prophylactic donor tricuspid annuloplasty in heart transplantation. J. Ann Thorac Surg. 2004;78:759-66.

19. Fiorelli Al, Stolf NA, Abreu Filho CA, Santos RH, Buco $\mathrm{FH}$, Fiorelli LR, et al. Prophylactic donor tricuspid annuloplasty in orthotopic bicaval heart transplantation. Transplant Proc. 2007;39(8):2527-30.

20. Pascual JMS, Fiorelli Al, Bellotti GM, et al. Prostacyclin in the management of pulmonary hypertension after heart transplantation. J Heart Transplant, 1990: 9:
644-51.

21. Fiorelli AI, Stolf NAG. Cuidados pós-operatório do transplante cardíaco. Rev Bras Cir Cardiovasc. 1996;11:30-8.

22. Miller LW, Naftal DC, Bourge RC, et al. Infection after heart transplantation: a multiintitutional story. $\mathrm{J}$ Heart Lung Transplant. 1994;13:381-93.

23. Billingham ME. Diagnosis of cardiac rejection by endomyocardial biopsy. J Heart Transplant. 1981;1:2530.

24. Fiorelli Al. Contribuição ao estudo da função do ventrículo esquerdo no pós-operatório de transplante cardíaco [Tese]. São Paulo: Faculdade de Medicina da Universidade de São Paulo; 1992.

25. Bacal F. Avaliação dos fatores de risco e dos métodos diagnósticos da doença vascular do enxerto em pacientes assintomáticos após transplante cardíaco [Tese]. São Paulo: Faculdade de Medicina da Universidade de São Paulo; 1999.

26. Billingham ME, Cary NRB, Hammond ME, et al. A working formulation for the standartization of nomenclature in the diagnosis of heart and lung rejection: Heart rejection study group. J Heart Transplant. 1990;9:587-601.

27. Costanzo-Nordim MR, Cooper D, Jessup M, et al. Heart transplantation: future developments. J Am Coll Cardiol. 1993;22:54-63.

28. Cascalho M, Li Platt JL. Xenotransplantation and other means of organ replacement. Nat Rev Immunol. 2001;1:154-60. 